\title{
Math Girls
}

\section{Reviewed by Mari Abe and Mei Kobayashi}

\author{
Math Girls \\ Hiroshi Yuki (translated by Tony Gonzalez) \\ Bento Books, 2011 \\ US\$24.99, 304 pages \\ ISBN-13: 978-0983951315
}

When we were asked to review Math Girls, translated from the Japanese novel 数学ガール, we were unsure how to respond. A cursory glance at the cover of the book might lead naïve prospective readers to assume it is a pro-math book to inspire young women to pursue a career in the mathematical sciences. A quick search on the Internet retrieved a comic book series and some free downloadable short stories. We wondered whether it might be an adaptation of a strange manga (Japanese comic book). Our curiosity was further piqued on finding that many of our female colleagues had received copies of the book as a gift from their husbands (who appear to be greater fans of the book than are their wives). So we decided to dive in.

We hope our review will answer some questions that came to our minds before reading the book. Will this tremendously popular Japanese book enjoy the same success and appeal with the American (or English-speaking) readership? Or will that special something, that je ne sais quoi, be lost in translation? Does the book successfully bridge cultural differences (AmericanJapanese, male-female)? Can a male writer portray young females engaging in mathematical dialog in a positive, exciting, and realistic light? Is the title appropriate? Or was it selected to be intentionally misleading? By the conclusion of the book, most of these questions seemed less relevant. The journey to the magical world of

Mari Abe and Mei Kobayashi are researchers at IBM Research in Tokyo. Their email addresses are respectively maria@jp.ibm.com and mei@jp.ibm.com. DOI: http://dx.doi.org/10.1090/noti886

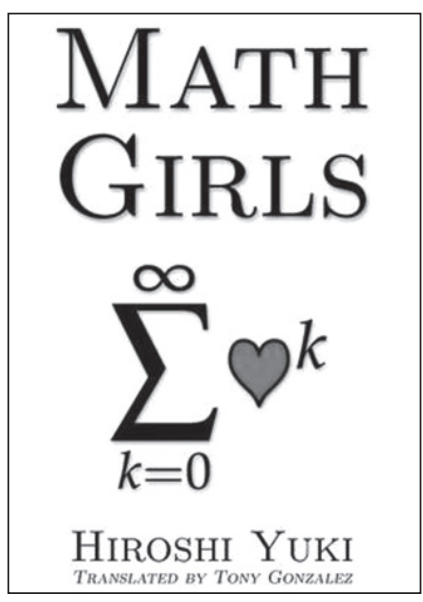

mathematics, the user-friendliness of the book, and its cheerful and playful prose make Math Girls an enjoyable read for a person with an inquisitive mind and mathematical inclination.

We do caution that Math Girls is not for everyone, particularly those who have little interest in or affinity for mathematics. The works of ancient Greek philosophers, scientists, and mathematicians form a leitmotif in the book, and some readers might find it fun to ferret out the clues and allusions to these works; those readers who are interested only in mathematics or are unfamiliar with Greek philosophy can remain oblivious to the references and still find much to enjoy. To help determine the suitability of the book as a gift, we provide a brief background sketch of the author, profiles of the characters, and remarks on the mathematical presentation. We do not summarize the mathematical content, as it is available in the table of contents. ${ }^{1}$

\section{Background of the Author}

Hiroshi Yuki was an established author of books on computer science until a series of vignettes posted on a whim on his website were serendipitously discovered by interested readers. In response to requests from fans, he compiled the stories into a book, Math Girls. The overwhelming positive response to the book was highly unusual for a book

\footnotetext{
${ }^{1}$ The table of contents is available for browsing online at http://www. amazon.com
} 
about mathematics. According to the publisher, ${ }^{2}$ Math Girls is "currently in its eighteenth printing in Japan, and has been one of the top 5 general interest mathematics books on amazon.com.jp since its original release in 2007."

A new Math Girls novel is being published almost annually (in Japanese), with each subsequent novel covering more advanced material. Major topics covered in the second volume are number theory, abstract algebra (groups, rings, and fields), methods of proof, Euler's identity, and Fermat's last theorem. The third volume introduces the Peano axioms, sets and logic, limits, trigonometry, and Gödel's incompleteness theorems; and the fourth, some topics from probability and mathematics in computer science, leading up to a discussion of randomized algorithms. Japanese comic books based on Math Girls have also been published, each featuring the imaginative talent of a different artist. The publisher hopes to release an English translation of Math Girls manga and the second novel in the series within the next twelve months. We review here the first Math Girls book published in 2007.

\section{Overview of the Plot and Profile of Characters}

Math Girls can be viewed as a collection of conversations between high school students about how to solve mathematics problems that require deep thought. Each chapter focuses on an historically significant problem which (in some cases) can be solved via more than one approach. In addition to tutoring readers on how to solve math problems, the conversations between the students provide examples of how to think about mathematics, approaches for tackling new problems, and ways to understand difficulties associated with learning.

The protagonist (and narrator) is an awkward male teenager who loves mathematics and has limited experience conversing with girls. He is simultaneously flattered and bewildered when a young, confident female math whiz named Miruka lavishes attention on him in the form of mathematical puzzles and quizzes. In the naming of this character, the author has invoked a typical play on words by the Japanese. Although the Japanese written characters differ, the pronunciations for the name Miruka and the phrase "Will you take a look at this?!" are identical.

Separately and equally unexpectedly, the protagonist is approached by an awkward younger girl named Tetra, who is interested in mathematics but suffers from a lack of confidence. Her introduction and the protagonist's follow-up question, "As in mono-, di-, tri-?" hint at the four elements from ancient Greece: earth, air, fire, and water. As

${ }^{2}$ Bento Books website: http://bentobooks.com/ 2011/09/math-girls-publication-announcement/. Accessed 6 Dec 2011. we read on, we find four main characters in the book, each of whom embodies characteristics that ancient Greeks associated with the elements. The name Tetra also references Empedocles' book Tetrasomia, or Doctrine of the Four Elements, in which the ancient Sicilian (Greek) philosopher, scientist, and healer proposed, "All matter is comprised of four 'roots' or elements of earth, air, fire and water ... the interaction of (which) is influenced by the relationship between the two great life energies of Love and Strife." ${ }^{3}$ The two characters who complete the world of four elements are Mr. Muraki, the mathematics teacher, and Mrs. Mizutani, the librarian.

The young and pure Tetra, who inspires the narrator in his math work, is the embodiment of air, which the Greeks regarded as a universal power and pure substance. Miruka is the embodiment of fire, an element said to provide clarity and commonly associated with energy, assertiveness, and passion. Mrs. Mizutani is the embodiment of water, an element associated with binding and separation. Tetra and/or Miruka and the narrator often meet in the library, whose caretaker, Mrs. Mizutani, dismisses (and separates) them at closing time. Mr. Kimura is the embodiment of earth, an element associated with seasons, crops, and fertility. He assigns new math problems that serve as catalysts that drive meetings between the narrator and the Math Girls (Miruka and Tetra). A Japanese reader would immediately realize Mr. Muraki's association with earth from his name, which means village tree, and Mrs. Mizutani's association with water, since her name means valley of water.

Three minor characters contribute to the boygirl/girl-boy subplots. AyAy is a talented pianist who is the president of Fortissimo, the school piano club. She is introduced to us when she gives a duet recital with Miruka. The Japanese word ay (more commonly spelled ai) has several different meanings depending on the Japanese character. It can mean love, meet, companion, or play pal (when combined with the character for play) or the indigo (blue) color or dye. ${ }^{4} \mathrm{~A}$ second minor

\footnotetext{
${ }^{3}$ T. Marks (1998), Elemental: The four elements-from Ancient Greek Science and Philosophy to Poetry, http:// www.webwinds.com/thalassa/elementa1.htm. Accessed 16 Dec 2011.

${ }^{4}$ In the original Japanese book, AyAy was named EiEi (エイエイ). Its pronunciation would be puzzling for Americans and would lead some to recall lyrics from old MacDonald's farm (http://en . wikipedia.org/wiki/ 01d_McDona1d_Had_a_Farm. . In Japanese there are several characters that are pronounced Ei. For example, in Japanese, eiei is an onomatopoeic word thought to evoke the sound of cheering (rooting) for someone or something. Alternatively, it can mean English, the first letter of the alphabet A, or to reflect or project (and is the first character for the compound word used for movie), or it can serve as the first character of the two-character word for nutrition.
} 
character, Kaito, ${ }^{5}$ a friend and classmate, provides a pair of tickets to a planetarium, which the narrator uses to take Tetra for what was intended to be a date (she falls asleep in the dark). In Japanese, kaito can have several meanings depending on the characters used in written form. Two common spellings consist of two characters, the first being sea (ocean) and the second, the constellation Ursa Major or the character to soar (fly). Several common words share the same pronunciation. Some nouns are answer (reply, response), answer (solution, e.g., of a math problem), the president, a small ferry; or the verb to dissolve (e.g., a party); or the verbs thaw or defrost (e.g., frozen foods) or decompress (a compressed or encoded file) in computer science. A third character, a flute, appears in the background when the narrator and Tetra meet in the library. In ancient Greece the music produced by flutes was associated with the voice of love. ${ }^{6}$

The characters' relationships, which are steeped in platonic love and conflict, are rather contrived and puerile. Nevertheless, they serve several purposes, the most obvious being to enliven the text and tie together what might otherwise be dreary and dry expository dialogs on mathematics. Another may be to inspire readers to look into the history of mathematics, particularly of ancient Greece. Unfortunately, many hints, jokes, and double entendres that work in Japanese are lost in translation and would be difficult to replicate in English, since the Japanese language (which uses three different types of characters) can be used more subtly to poke fun. For example, Miruka could be translated as CeeCee or C.C. (similar to "J.R.", as in "Who shot J.R.?"), AyAy as Venus, and Mr. Muraki as Mr. Arbre. However, a second meaning that could be associated with Muraki $=\mathrm{Mu}+\mathrm{Aki}$ = never grow bored cannot be adequately captured in translation.

\footnotetext{
${ }^{5}$ The translator changed the name of this character from Tsunomiya (東宮) in the Japanese text due to its length and the difficulty in pronunciation for Western readers lacking familiarity with Japanese morphology. In addition, Tsunomiya would have been the only character to be addressed by his last name by other students, which would be very odd in the United States. Tsunomiya means Eastern residence of the Emperor, referring to Tokyo (東京), which means Eastern Capital.

${ }^{6}$ In Greek myths the birth of the flute is attributed to Pan, a creature who is half human and half goat. One day when Pan is scampering about in a forest, he encounters Syrinx and immediately falls in love. However, she panics from unwanted advances by the odd-looking creature and flees to the water's edge. In response to Pan's pleas for help, Zeus turns Syrinx into a reed, and the heartbroken Pan cuts and bundles the reed to make panpipes. He uses the panpipes to "give voice to his pangs of love." C. Puscouiu, B. White, History of the Panflute, http://pan-flute. com/history// Accessed 22 Dec 2011.
}

For reasons we may only venture to guess, the name of the narrator remains a mystery through the entire book, perhaps suggesting that he can be any adolescent male. Omission of a name and clear identity helps readers travel to the mathematical world of the narrator and empathize with his challenges.

Some readers may become weary of the girl-boy subplots and the simplistic text, replete with symbolism from ancient Greek myths and philosophy. If they accept Math Girls as a mathematics textbook in disguise and the girl-boy encounters as (sometimes trite and sometimes more successful) attempts to introduce approaches to thinking as a professional mathematician, the book will read swimmingly. Remarks by the author in the Afterword section may go over better with the Japanese male readership than with females and Americans due to cultural differences:

This fascination one can have with mathematics is similar to the fascination a boy can have with a girl. You try to solve a difficult problem, but you can't seem to find an answer-you don't even know where to start. But there's something about it that draws you in and won't let go. You know that something wonderful waits, if you can only coax it into sharing its secrets. That's the kind of feeling I hope this book has brought to you. (p. 271)

\section{Mathematics in Math Girls}

Mathematics is clearly the superstar of this novel, with beautiful derivations and proofs. Equally important are the one-on-one discussions that illustrate the need for patient and thoughtful nurturing of young people interested in mathematics. We were told by readers that they found the math problems much more interesting than textbookstyle assignments they had encountered in school. They also enjoyed the emphasis on thinking-and different ways of thinking-about a problem. Explanations of different approaches to solving a problem were "exciting", with each approach boasting its own unique type of mathematical elegance and finesse or high practical value (e.g., speed in computation).

The first chapter eases us into the playful world of mathematics. The discussions center on the discovery of patterns in numerical sequences and puzzles based on Fibonacci sequences, primes, and powers of integers. To solve for the $n$th Fibonacci number, a computer science major accustomed to coding solutions would most likely code a recursive method for finding a solution for an input natural number $n$. The idea of and the process involved in deriving a closed-form formula 
seemed exciting and new to CS majors with whom we talked.

The final puzzle in Chapter 1 stumped the protagonist (as well as us). Upon hearing the answer, he is unembarrassed, unapologetic, and even a bit defiant:

What I didn't like about this problem was ... [i]t relies on memorization. Math isn't about dredging up half remembered formulas. It's about making new discoveries. Sure there are some things that require rote memorization ... but math is not like that. With a math problem you have a set of rules. You have tools and materials... math is not about memorizing, it's about thinking. Or at least that's what it is to me. (p. 7)

This is the first of a series of impromptu philosophical discussions that magically pop up in the midst of mathematical dialogs throughout the book. Questions such as, "If [a] sequence goes on forever, at what point can you figure out the rest?" are answered in a delightfully casual, adolescent manner. "There's always a chance that the pattern will suddenly change somewhere beyond what you've seen ... But that's the way the world works. You never know what's going to come next. Predictions fail. Check this out ... [followed by an abrupt change in topic]" (p. 9). These moments of thoughtful inquiry sprout and dissipate at a moment's whim, typifying adolescent dialog. More often than not, they work.

The next several chapters happily zip along in a similar tone, with increasingly more sophisticated and interesting mathematical concepts and derivations (derivatives (continuous and discrete), harmonic numbers, Taylor series, the Basel Problem, partitions, ...). At the same time, the book helps readers understand the difficulties and hurdles associated with human learning. Among the general populace, for some inexplicable and unjustified reason, mathematics has come to symbolize the horrors of required schoolwork. When the narrator falls into a mathematical rut, Miruka consoles him with wisdom that all math majors gratefully received at some point in their careers from their teachers:

"I couldn't solve it," I said, "I got lost." ... "You're hardly the first mathematician to go down the wrong path. But you know what? If you don't go looking, you'll never know what you might have found. If you don't try new things, you'll never know what you're capable of. We're on a journey here. Sometimes we get tired, and sometimes we get lost. But that's no reason to give up. ... If you get tired, rest. If you get lost, backtrack. That's what the journey is all about." (p. 252)

Math Girls is not a novel. To dub it a "romance" or "love story" would be grossly misleading. It is a math book that clearly reads like one written by an author who truly loves mathematics. Some view the intended message of the book to be about the awkwardness of teenagers, the freedom of exploring interests outside of prescribed courses of study, and the delights of self-directed learning, as can be gleaned from conversations in which the narrator urges Tetra to play with math until she is satisfied with explanations, to see the beauty in elegant proofs and approaches, and not to focus on solving math problems as a means to some other ends (grades, a job, etc.).

Though not intentionally written for a male audience, our guess is that Math Girls will resonate more highly with males than with females, due (in part) to the depth with which the male narrator is portrayed compared to the female characters. However, we enjoyed the read and look forward to immersing ourselves in the magical world of mathematics in future volumes.

In closing, we note that only five years have passed since former Harvard president Lawrence $H$. Summers resigned before facing an all but certain vote of no confidence following several major and divisive actions, including a public speech in which he proposed that women might lack an intrinsic aptitude for math and science. ${ }^{7}$ Last year Princeton celebrated the fiftieth anniversary of its first female degree candidate. The university organized an event, She Roars, "to celebrate and to reflect on the evolving role of women ... to mark the contributions that women have made ... as well as the challenges that still confront (them)."8

Challenges and myths still abound. Interestingly, Math Girls was first published in 2007 in Japan, a country considered more backward than the United States in gender equality attitudes and policies. It is refreshing to have a popular book with females actively participating in mathematical discussions and tackling historically significant math problems. We applaud the author for putting politics aside and focusing on the beauty of mathematics and the development of friendships through collaboration and for highlighting the importance of thinking and understanding and appreciating different perspectives in approaching

\footnotetext{
${ }^{7}$ A. Finer, P. D. Healy, K. Zernike (2006), "President of Harvard resigns, ending stormy 5-year tenure", NY Times online:/http://www. nytimes . com/2006/02/22/ education/22harvard.htm1. Accessed 5 Dec 2011.

${ }^{8}$ C. Ciatt (2011), "She Roars" conference celebrates women at Princeton: http://www.princeton. edu/main/news/archive/530/34/23146/index. xm1?section=topstories. Accessed 5 Dec 2011.
} 
problems (perhaps not just mathematical). Seen in this context, the book serves as a lively and fun public ambassador from the world of mathematics to the general public and helps free readers from damaging and pernicious stereotypes.

\section{Addendum}

Curious readers may sample the first two chapters of Math Girls as free downloads from the publisher's website. ${ }^{9}$ Since the content of the book advances quickly in mathematical difficulty,

${ }^{9}$ Math Girls homepage, sample section: http:// bentobooks.com/wp-content/uploads/2011/10/ Math-Girls-Sample.pdf. we found them to be a bit unrepresentative of the book; more specifically, we found them to be among the least interesting. Readers who experience difficulty following the math in these samples are unlikely to enjoy the remainder of the text. Unfortunately, a large portion of the recommended supplementary readings were written in Japanese and have not been translated.

\section{Acknowledgments}

We would like to thank the Notices and Bento Books for the opportunity and privilege to read and review Math Girls, and Tony Gonzalez for his friendly and courteous help in providing us background information.

\section{Book Review}

\section{Magical Mathematics}

\section{Reviewed by Donovan H. Van Osdol}

\begin{tabular}{l} 
Magical Mathematics: The Mathematical Ideas \\
that Animate Great Magic Tricks \\
Persi Diaconis and Ron Graham \\
Princeton University Press, 2011 \\
US\$29.95, 258 pages \\
ISBN-13: $978-0691151649$ \\
\hline
\end{tabular}

When I agreed to review this book for the Notices, I did not know that the perfect review had already been written-by Martin Gardner-and that it appeared as the preface to the book itself! In the end, I decided to write up my two cents' worth in hopes of encouraging you to buy Magical Mathematics for yourself. Of course, if you want to read the perfect review without buying the book or reading this review, you are likely to be able to read the preface by having a "Look Inside" the book at Amazon . com.

To give a vignette of what you can expect to find flowing from the pens of Diaconis and Graham, let me describe a magic trick for you. I'm going to write a word on a piece of paper, fold it into fourths so as to hide the word, and put the paper beneath this brick here on the table before us (we need something really weighty to protect my prediction from being tampered with!). To do your part in

Donovan H. Van Osdol is professor of mathematics, emeritus, at the University of New Hampshire. His email address is dvanosdo@tampabay.rr.com.

DOI: http://dx.doi.org/10.1090/noti875

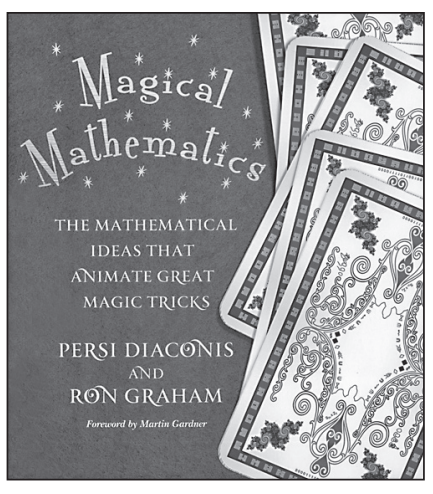

this test of my ability to forecast the future, I want you to pick any word (of which there are thirty-six) in the first sentence of the preceding paragraph. Notice that I have no control over your choice: there's nothing up my sleeves! Let's call this word a "key" word.

Now please count the number of alphabetic characters in your key word and move forward in the paragraph that many words to arrive at a new key word. For example, if the initial "to" in that first sentence were your chosen key word, then your next key word would be "this". Got it? Okay, now repeat this process (so that in our example your next key word would be "Notices"), over and over, until you can't go any further in the second sentence (which ends with "yourself": always a good place to stop!). There are twenty-three words in that sentence, so there's not a very good chance that I could know your final key word before you started, right? Good, I agree... But wait, there's this piece of paper under this brick here where I wrote a word... Would you pick up the brick, look 